\title{
Synthesis and characterization of new 2-(alkylamino)acetamides
}

\author{
Teresa Mancilla,* Luis S. Zamudio-Rivera, Lourdes Carrillo, \\ Hiram I. Beltrán and Norberto Farfán
}

\author{
Departamento de Química, Centro de Investigación y de Estudios Avanzados del Instituto \\ Politécnico Nacional, Apdo. Postal 14-740, 07000 México, D. F., MÉXICO \\ E-mail: tmancill@mail.cinvestav.mx
}

(received 27 Jun 03; accepted 24 Sep 03; published on the web 25 Sep 03)

\begin{abstract}
Seven new 2-(alkylamino)acetamides have been synthesized and characterized by ${ }^{1} \mathrm{H},{ }^{13} \mathrm{C}$ NMR, NOESY experiments, infrared and mass spectrometry. The structure of 2(diphenylmethylamino)acetamide $\mathbf{3 b}$ was further established by a single crystal x-ray diffraction study. The NMR study of the transformation of several 2-(alkylamino)acetamides to their corresponding morpholin-2-ones shows that these species are thermodynamically favored through preferred conformations as determined by theoretical calculations of $\mathbf{3 h}$.
\end{abstract}

Keywords: Acetamides, amides, synthesis, spectroscopy, x-ray

\section{Introduction}

A number of 2-(alkylamino)acetamides have been shown to possess antiarrhythmic, ${ }^{1}$ anticonvulsive, $^{2}$ anti-inflammatory ${ }^{3}$ and hypotensive ${ }^{4}$ activity. They have also been used as precursors in the synthesis of vicinal diamides, morpholin-2-ones, ${ }^{5}$ and as ligands in the synthesis of organometallic compounds with potential anti-tumor activity. ${ }^{6}$

2-(Alkylamino)acetamides have been prepared by reaction of 2-chloro- $N, N$-dimethylacetamide or 2-(alkylamino)methylacetate with amines and $\beta$-aminoalcohols, in the presence of sodium bicarbonate or triethylamine. ${ }^{5,7-8}$ It is noteworthy that the reaction of 2-chloro- $N, N$ dimethylacetamide with ephedrines, in the presence of sodium bicarbonate, under reflux of benzene for 20 hours provides both 2-(alkylamino)acetamides and morpholin-2-ones, while the use of triethylamine as base yields exclusively the corresponding 2-(alkylamino)-acetamides. In contrast, when this reaction is carried out under reflux of xylene, the morpholin-2-one is formed exclusively. ${ }^{5}$ Our current interest in 2-(alkylamino)acetamides prompted us to develop better reaction condition to synthesize these compounds in good yields. Thus, we describe herein the synthesis and characterization of seven new 2-(alkylamino)acetamides 3a-j (Scheme 1). The structure of compound $\mathbf{3 b}$ was further established by a single-crystal X-ray diffraction study. 


\section{Results and Discussion}

2-(Alkylamino)acetamides 3a-j were prepared in yields between $73-98 \%$ by the reaction of 2 bromoacetamide 1 with 3-aminobenzyl alcohol 2a, aminodiphenylmethane $\mathbf{2 b}$, (1S,2S)-(+)pseudoephedrine 2d, (1R,2R)-(-)-pseudoephedrine 2e, (1R,2S)-(-)ephedrine $\mathbf{2 f}$ and $(1 S, 2 R)-$ $(+)$ ephedrine 2g, 2-(methylamino)ethanol 2h, N-benzylethanolamine $2 \mathbf{i}$ and (S)-(+)pyrrolidinemethanol $2 \mathbf{j}$, in the presence of $\mathrm{KHCO}_{3}$ under reflux in acetonitrile for 6 hours. Compound $3 \mathbf{c}$ was obtained by reaction of $\mathbf{1}$ and $\mathbf{2 a}$ in a 2:1 molar ratio.
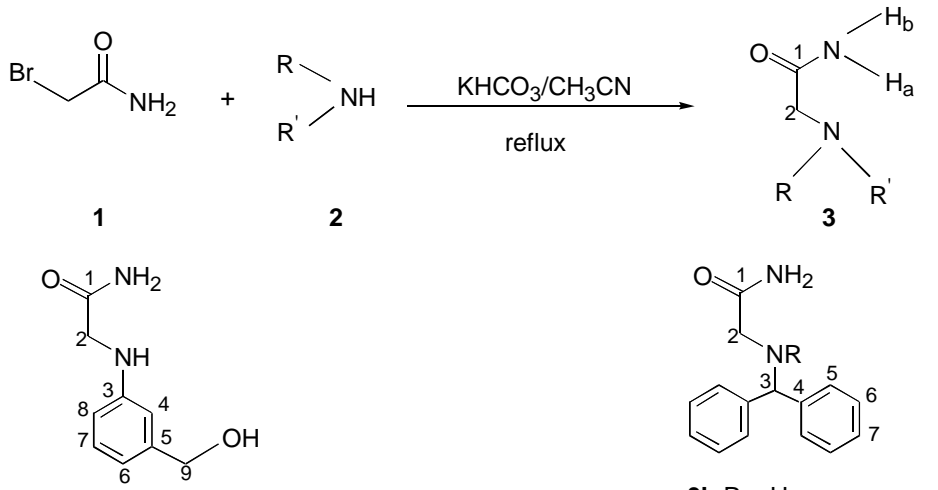

$3 a$

3b $\mathrm{R}=\mathrm{H}$

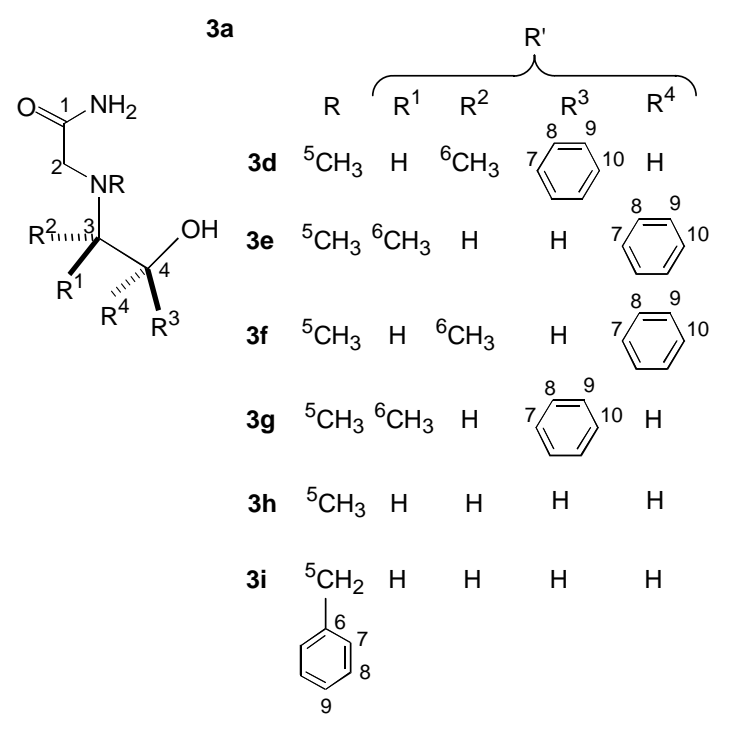

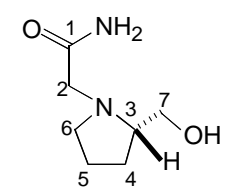

3j

\section{Scheme 1}

As confirmed by ${ }^{1} \mathrm{H}$ NMR the reaction of bromoacetamide 1 and $\beta$-aminoalcohols $2 \mathrm{f}, 2 \mathrm{~h}$ and $2 \mathrm{j}$ leads to 2 -(aminoalkyl)acetamides $3 \mathrm{f}, 3 \mathrm{~h}$ and $3 \mathrm{j}$ which are transformed into the corresponding morpholin-2-ones ${ }^{5,12}$ in aproximatly $30 \%$, after 12 hours under reflux except for $3 \mathrm{j}$. Moreover, 2 (aminoalkyl)acetamides $3 \mathrm{f}, 3 \mathrm{~h}, 3 \mathrm{i}$ and $3 \mathrm{j}$ were allowed to stand for one month in chloroform solution which resulted in $40 \%$ conversion to the morpholine-2-ones, except for $3 \mathrm{j}$ (Scheme 2). These data suggests that the transformation of $3 \mathrm{f}, 3 \mathrm{~h}$, and $3 \mathrm{i}$ into the corresponding morpholin-2- 
ones is thermodynamically favored and proceeds through a prefered conformation which was calculated for $3 \mathrm{~h}$ using a theoretical (AMI, Ab initio STO-3G and 3-21G) approach. ${ }^{13}$ Figure 1 depicts the particular conformation where there is an intramolecular interaction between the $\mathrm{OH}$ group and the carbonyl group, that increases nucleophilicity of the carbonyl group and favors formation of the corresponding morpholin-2-one.
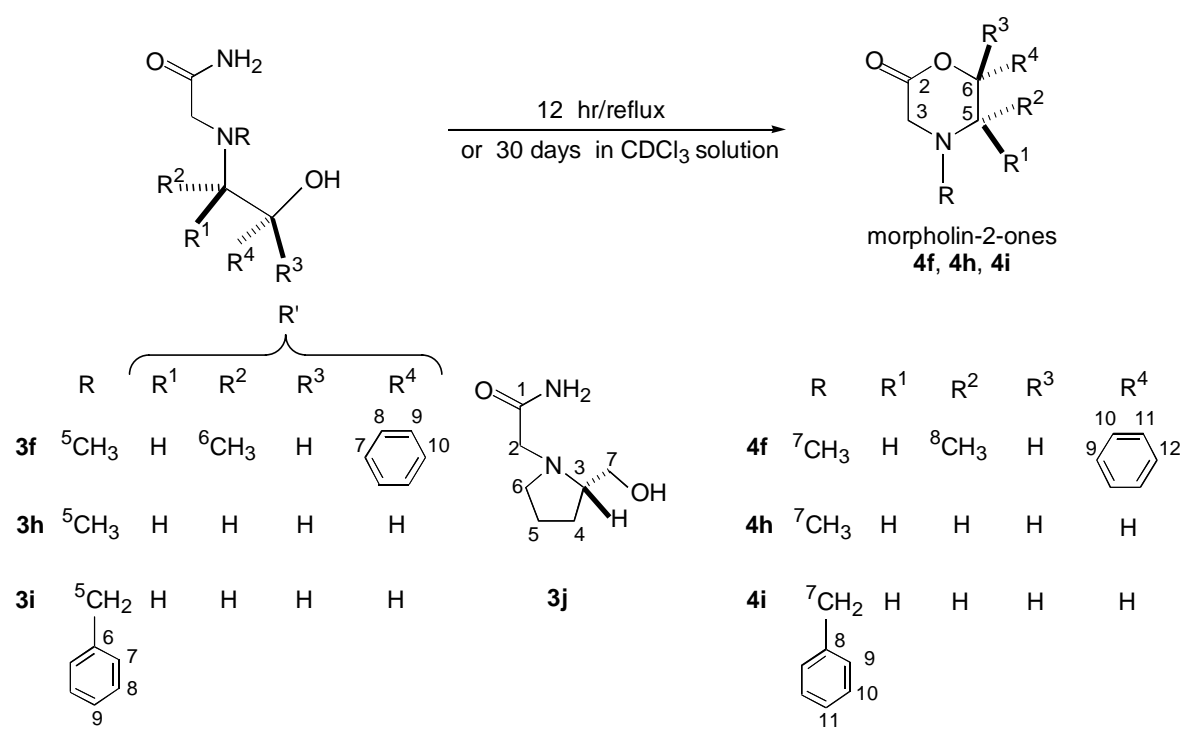

3j

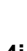

4i $\quad{ }^{7} \mathrm{CH}_{2} \quad \mathrm{H} \quad \mathrm{H} \quad \mathrm{H} \quad \mathrm{H}$ $\underbrace{8}_{11} 9$
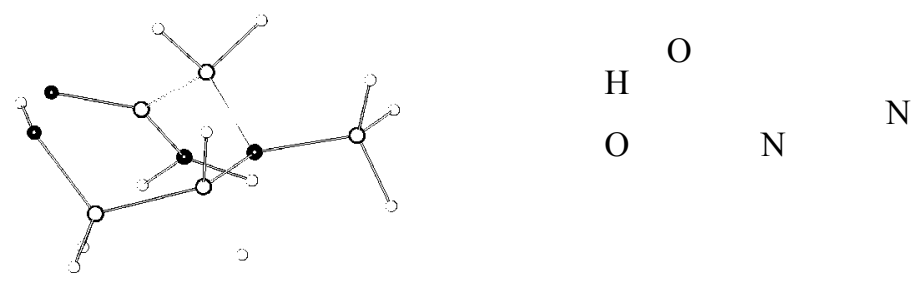

\section{Scheme 2}

\section{Figure 1}

\section{NMR spectroscopy}

The ${ }^{1} \mathrm{H}$ NMR spectra of compounds 3a-j exhibit an AB system for the amidic protons $\left(\mathrm{NH}_{2}\right)$ due to partial $\mathrm{C}=\mathrm{N}$ double bond character (Table 1). Unambiguous assignment of these protons was attained by NOESY experiments which revealed an interaction of the proton shifted to lower field with $\mathrm{H}-2$, evidencing that it is anti to the carbonyl group, in agreement with analogous systems reported in the literature. ${ }^{9}$ The spectra of compounds $\mathbf{3 a - c}$, $\mathbf{3 h}$ and $\mathbf{3 i}$ exhibit a single signal for the methylene protons at position 2, while compounds $\mathbf{3 d}-\mathbf{g}$ and $\mathbf{3 j}$ give an $\mathrm{AB}$ system. Since the pyrrolidyl and $\mathrm{H}-7$ protons in compound $\mathbf{3} \mathbf{j}$ show a complex pattern, unambiguous identification of $\mathrm{H}-7$ was established using selective decoupling experiments. Thus irradiation of $\mathrm{H}-3$ simplified the $\mathrm{ABX}$ system for $\mathrm{H}-7$ to an $\mathrm{AB}$ system. 
Table 1. ${ }^{1} \mathrm{H}$ NMR data of $\mathbf{3 a}-3 \mathbf{j}$ : $\delta_{\mathrm{H}}$ and $\delta_{\mathrm{N}}[\mathrm{ppm}]$ and coupling constants $J[\mathrm{~Hz}]$

\begin{tabular}{|c|c|c|c|c|c|c|}
\hline & Solvent & $\mathrm{H}-2$ & $\mathrm{NH}_{\mathrm{a}}$ & $\mathrm{NH}_{\mathrm{b}}$ & $\mathrm{R}$ & $\mathrm{R}^{\prime}$ \\
\hline \multirow[t]{5}{*}{ 3a } & DMSO-d $\mathrm{d}_{6}$ & 3.57 & 7. & 7.11 & 3.68 & H-4 6.53 \\
\hline & & & 2 & & & H-6 $6.547 .8^{\mathrm{b}}$ \\
\hline & & & 3 & & & H-7 $7.03 \quad 7.8^{\mathrm{b}}$ \\
\hline & & & & & & H-8 $6.42 \quad 7.8^{b}$ \\
\hline & & & & & & H-9 4.38 \\
\hline \multirow[t]{3}{*}{ 3b } & $\mathrm{CDCl}_{3}$ & 3.24 & 6.88 & 6.07 & 2.16 & H-3 4.83 \\
\hline & & & & & & H-5,6 7.30-7.36 \\
\hline & & & & & & $\mathrm{H}-7 \quad 7.23 \quad 7.0^{\mathrm{b}}$ \\
\hline \multirow[t]{4}{*}{ 3c } & DMSO-d $\mathrm{d}_{6}$ & 3.13 & 7.64 & 7.06 & H-2 3.13 & H-3 5.23 \\
\hline & & & & & $\mathrm{NH}_{\mathrm{a}} 7.64$ & H-5 $7.47 \quad 7.3^{b}$ \\
\hline & & & & & $\mathrm{NH}_{\mathrm{b}} 7.06$ & H-6 $7.307 .3^{b}$ \\
\hline & & & & & & H-7 $7.207 .3^{b}$ \\
\hline \multirow[t]{4}{*}{ 3d } & DMSO$_{-} \mathrm{d}_{6}$ & $\mathrm{H}_{\mathrm{A}} 3.0716 .1^{\mathrm{a}}$ & 7.68 & 7.15 & H-5 2.23 & $\mathrm{H}-32.648 .8^{\mathrm{b}}, 6.6^{\mathrm{b}}$ \\
\hline & & $\mathrm{H}_{\mathrm{B}} 2.8816 .1^{\mathrm{a}}$ & & & & $\mathrm{H}-44.328 .8^{\mathrm{b}}$ \\
\hline & & & & & & H-6 $0.59 \quad 6.6^{\mathrm{b}}$ \\
\hline & & & & & & $\mathrm{H}-8,9,10 \quad 7.20-7.23$ \\
\hline \multirow[t]{4}{*}{ 3e } & DMSO-d $_{6}$ & $\mathrm{H}_{\mathrm{A}} 3.0516 .1^{\mathrm{a}}$ & 7.64 & 7.16 & H-5 2.24 & $\mathrm{H}-32.648 .8^{\mathrm{b}}, 6.6^{\mathrm{b}}$ \\
\hline & & $\mathrm{H}_{\mathrm{B}} 2.8516 .1^{\mathrm{a}}$ & & & & H-4 $4.348 .8^{\mathrm{b}}$ \\
\hline & & & & & & H-6 $0.60 \quad 6.6^{\mathrm{b}}$ \\
\hline & & & & & & H- $8,9,10 \quad 7.21-7.25$ \\
\hline \multirow[t]{4}{*}{$3 f$} & $\mathrm{CDCl}_{3}$ & $\mathrm{H}_{\mathrm{A}} 2.9616 .8^{\mathrm{a}}$ & 6.31 & 5.53 & H-5 2.21 & $\mathrm{H}-32.787 .3^{\mathrm{b}}, 6.6^{\mathrm{b}}$ \\
\hline & & $\mathrm{H}_{\mathrm{B}} 2.9316 .8^{\mathrm{a}}$ & & & & H-4 $4.56 \quad 7.3^{b}$ \\
\hline & & & & & & H-6 $1.01 \quad 6.6^{\mathrm{b}}$ \\
\hline & & & & & & $\mathrm{H}-8,9,10 \quad 7.25-7.35$ \\
\hline \multirow[t]{4}{*}{$3 g$} & $\mathrm{CDCl}_{3}$ & $\mathrm{H}_{\mathrm{A}} 2.9616 .8^{\mathrm{a}}$ & 6.32 & 5.54 & $\mathrm{H}-5 \quad 2.20$ & H-3 $2.767 .3^{b}, 6.6^{b}$ \\
\hline & & $\mathrm{H}_{\mathrm{B}} 2.9216 .8^{\mathrm{a}}$ & & & & H-4 $4.557 .3^{b}$ \\
\hline & & & & & & H-6 $1.016 .6^{b}$ \\
\hline & & & & & & $\mathrm{H}-8,9,10 \quad 7.25-7.35$ \\
\hline \multirow[t]{2}{*}{$3 \mathbf{h}$} & $\mathrm{CDCl}_{3}$ & 3.06 & 7.66 & 6.80 & H-5 2.33 & H-3 $2.595 .1^{b}$ \\
\hline & & & & & & H-4 $3.65 \quad 5.1^{b}$ \\
\hline \multirow[t]{2}{*}{$3 \mathbf{i}$} & $\mathrm{CDCl}_{3}$ & 3.11 & 7.30 & 6.40 & H-5 3.67 & H-3 2.68 $5.1^{b}$ \\
\hline & & & & & $\mathrm{H}-7,8,9 \quad 7.24$ & $\mathrm{H}-43.635 .1^{\mathrm{b}}$ \\
\hline \multirow[t]{5}{*}{$3 \mathbf{j}$} & $\mathrm{CDCl}_{3}$ & $\mathrm{H}_{\mathrm{A}} 3.4516 .7^{\mathrm{a}}$ & 7.43 & 6.60 & H-3 $2.73 \quad 3.7^{\mathrm{b}}, 4.7^{\mathrm{b}}$ & H-5 $1.63-1.82$ \\
\hline & & $\mathrm{H}_{\mathrm{B}} 3.2016 .7^{\mathrm{a}}$ & & & $\mathrm{H}-4_{\mathrm{A}} \quad 1.84-1.97$ & $\mathrm{H}-6_{\mathrm{A}} 3.169 .1^{\mathrm{a}}$ \\
\hline & & & & & $\mathrm{H}-4_{\mathrm{B}} \quad 1.63-1.83$ & $\mathrm{H}-6_{\mathrm{B}} 2.409 .1^{\mathrm{a}}$ \\
\hline & & & & & & $\mathrm{H}-7_{\mathrm{A}} 3.6011 .3^{\mathrm{a}}, 3.7^{\mathrm{b}}$ \\
\hline & & & & & & $\mathrm{H}-7_{\mathrm{B}} 3.4711 .3^{\mathrm{a}}, 3.7^{\mathrm{b}}$ \\
\hline
\end{tabular}


The ${ }^{13} \mathrm{C}$ NMR chemical shift for C-2 in compounds 3a-j is in the range between 46.76 to 59.92 ppm, which is shifted to higher frequency compared with bromoacetamide $(\delta=29.05 \mathrm{ppm})$. Assignment of the signals for C-2, C-4 and C-5 in 3h, C-2, C-3, C-8 and C-9 in 3i and C-2, C-3, C8 and $\mathrm{C}-9$ in $3 \mathbf{j}$, were obtained by ${ }^{13} \mathrm{C}-{ }^{1} \mathrm{H}$ HETCOR techniques. Unambiguous assignment of C-3 and $\mathrm{C}-5$ in $3 a$ was attained from a ${ }^{13} \mathrm{C}-{ }^{1} \mathrm{H}$ COLOC spectra. Table 2 summarizes the ${ }^{13} \mathrm{C}$ NMR data for compounds $\mathbf{3 a}-\mathbf{j}$.

Table 2. ${ }^{13} \mathrm{C}$ NMR data of $\mathbf{3 a - 3 j :} \delta_{\mathrm{C}}[\mathrm{ppm}]$

\begin{tabular}{llllllllllll}
\hline & Solvent & C-1 & C-2 & C-3 & C-4 & C-5 & C-6 & C-7 & C-8 & C-9 & C-10 \\
\hline 3a & DMSO-d & 172.52 & 46.76 & 148.13 & 110.15 & 143.25 & 114.87 & 128.58 & 110.88 & 63.23 & \\
3b & CDCl $_{3}$ & 174.47 & 50.45 & 66.74 & 142.83 & 127.26 & 128.66 & 127.40 & & & \\
3c & DMSO-d $_{6}$ & 172.81 & 54.57 & 70.66 & 142.16 & 128.22 & 128.37 & 127.07 & & & \\
3d & DMSO-d $_{6}$ & 173.05 & 57.76 & 64.69 & 74.53 & 37.22 & 8.97 & 143.38 & 127.18 & 127.93 & 127.18 \\
3e & DMSO-d $_{6}$ & 173.05 & 57.76 & 64.69 & 74.53 & 37.22 & 8.97 & 143.38 & 127.18 & 127.93 & 127.18 \\
3f & $\mathrm{CDCl}_{3}$ & 174.95 & 58.27 & 64.96 & 75.91 & 38.74 & 9.85 & 143.74 & 126.42 & 128.34 & 127.60 \\
3g & $\mathrm{CDCl}_{3}$ & 174.95 & 58.27 & 64.96 & 75.91 & 38.74 & 9.85 & 143.74 & 126.42 & 128.34 & 127.60 \\
3h & $\mathrm{CDCl}_{3}$ & 175.20 & 59.92 & 59.12 & 61.80 & 42.90 & & & & & \\
3i & $\mathrm{CDCl}_{3}$ & 175.22 & 57.88 & 57.29 & 59.58 & 59.36 & 137.96 & 128.52 & 128.89 & 127.46 & \\
3j & $\mathrm{CDCl}_{3}$ & 175.70 & 58.65 & 65.71 & 27.17 & 23.68 & 55.93 & 63.72 & & & \\
\hline
\end{tabular}

\section{Mass spectrometry}

In general the $70 \mathrm{eV}$ EI mass spectra do not show the molecular ion, except for 3a that gives the molecular ion at $\mathrm{m} / \mathrm{z}=180(36 \%)$. All spectra show the fragment ions $\left[\mathrm{RR}^{\prime} \mathrm{NCH}_{2}\right]^{+}$and $\left[\mathrm{H}_{2} \mathrm{NCO}^{+}\right.$ due to the $\mathrm{C}_{1}-\mathrm{C}_{2}$ bond rupture and the fragment ion $[\mathrm{R}-\mathrm{N}=]^{+}$, except for $3 \mathrm{c}$.The fragment ions at

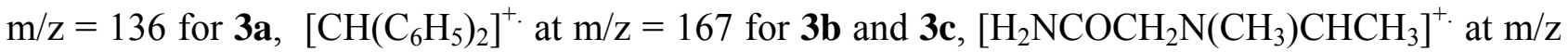
$=115$ for $\mathbf{3 d}-\mathbf{3 g}, \mathrm{m} / \mathrm{z}=44$ for $\mathbf{3 h},\left[\mathrm{C}_{7} \mathrm{H}_{7}\right]^{+}$at $\mathrm{m} / \mathrm{z}=91$ for $\mathbf{3 i}$ and $\left[\mathrm{M}-\mathrm{CH}_{2} \mathrm{OH}\right]^{+}$at $\mathrm{m} / \mathrm{z}=127$ for $3 \mathbf{j}$, correspond to the base peaks. The proposed fragmentation is shown in Scheme 3. 


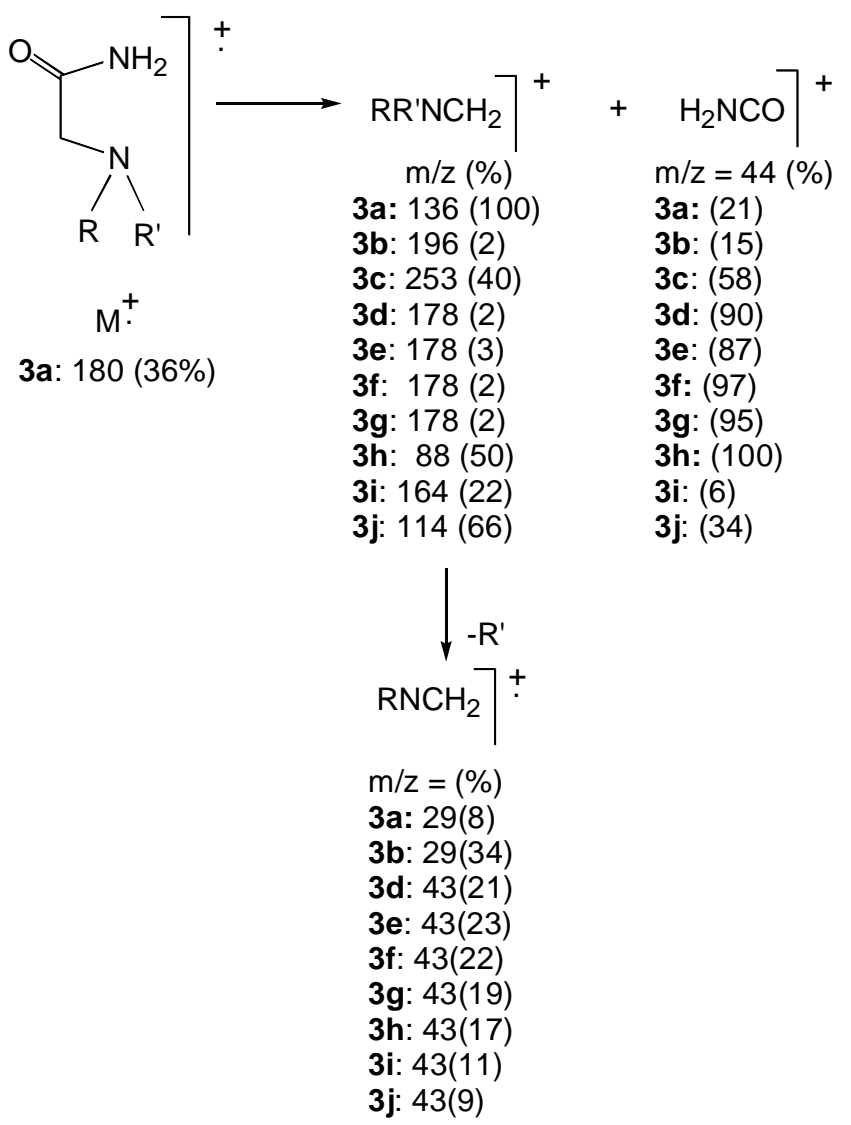

\section{Scheme 3}

\section{Infrared spectroscopy}

The IR spectra of compounds 3a-j show the absorption band characteristic of the amide I and II in the range between 1676-1638 and 1672-1588 $\mathrm{cm}^{-1}$, respectively, as well as absorption bands for the $\mathrm{NH}$ and $\mathrm{OH}$ groups in the range between $3432-3178 \mathrm{~cm}^{-1}$.

\section{X-Ray diffraction}

Suitable crystals of $\mathbf{3 b}$ for X-ray analysis were obtained from chloroform/hexane, the molecular structure and crystallographic numbering is shown in figure 2. In general the bond distances are within the values characteristic of amides. ${ }^{10}$ Selected bond lengths are: $\mathrm{N}_{1}-\mathrm{H}_{1 \mathrm{a}} 0.925, \mathrm{~N}_{1}-\mathrm{H}_{1 \mathrm{~b}} 0.864$, $\mathrm{C}_{1}-\mathrm{O}_{1} 1.227$ (2), $\mathrm{C}_{1}-\mathrm{N}_{1} 1.318$ (2), $\mathrm{C}_{3}-\mathrm{N}_{2} 1.478$ (2) and $\mathrm{C}_{2}-\mathrm{N}_{2} 1.464$ (2) A. Torsion angles for the $\mathrm{O}_{1}$ $\mathrm{C}_{1}-\mathrm{N}_{1}-\mathrm{H}_{1 \mathrm{a}}$ and $\mathrm{O}_{1}-\mathrm{C}_{1}-\mathrm{N}_{1}-\mathrm{H}_{1 \mathrm{~b}}$ fragments are: $172.51^{\circ}$ and $1.17^{\circ}$ respectively, this indicates that this part of the molecule is flat due to the resonance effect present between the O1-C1-N1 atoms. The molecular structure shows the following intermolecular contacts: $\mathrm{O}_{1}{ }^{\cdots \cdots} \mathrm{H}_{2 \mathrm{a}} 2.540, \mathrm{O}_{1}{ }^{\cdots \cdots} \mathrm{H}_{5} \quad 2.514$, $\mathrm{O}_{1}{ }^{\cdots \cdots} \mathrm{H}_{1 \mathrm{a}} 1.936$ and $\mathrm{N}_{2} \cdots \mathrm{H}_{1 \mathrm{~b}}$ 2.306, which are significantly shorter than the sum of the van der Waals radii for oxygen and hydrogen atoms $(2.70 \AA)$ as well as nitrogen and hydrogen $(2.75 \AA) .{ }^{11}$ In addition, the following intramolecular contacts are observed between $\mathrm{N}_{2} \cdots \cdots \cdot \mathrm{H}_{3} 2.030, \mathrm{~N}_{2} \cdots \cdots \cdot \mathrm{H}_{2 b}$ $1.967, \mathrm{~N}_{2}{ }^{\cdots \cdots \cdot} \mathrm{H}_{2 \mathrm{a}} 2.498, \mathrm{~N}_{2}{ }^{\cdots \cdots \cdot} \mathrm{H}_{5} 2.500, \mathrm{O}_{1}{ }^{\cdots \cdots \cdot} \mathrm{H}_{2} 2.570$ and $\mathrm{O}_{1}{ }^{\cdots \cdots \cdot} \mathrm{H}_{1 \mathrm{~b}} 2.413 \AA$. 


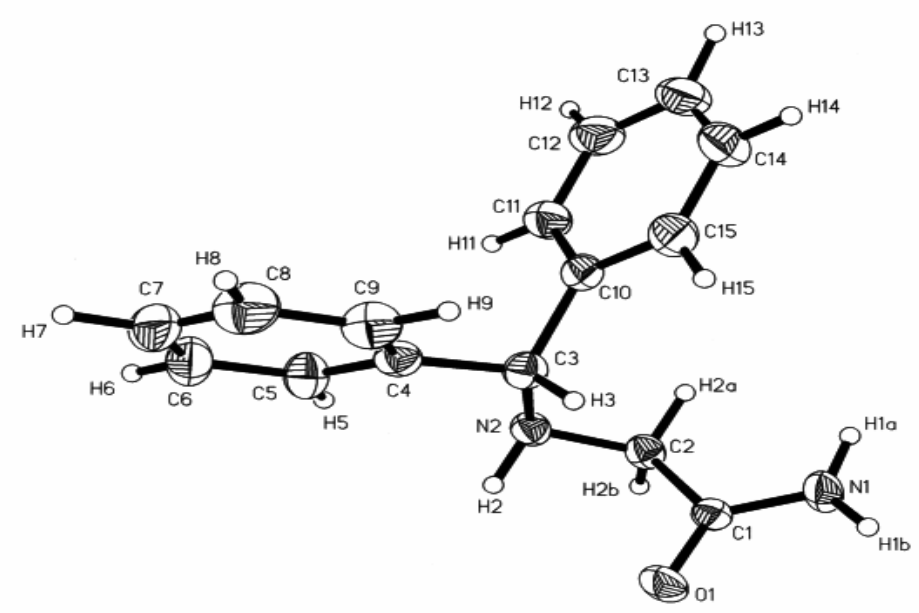

Figure 2

\section{Conclusions}

Optimization of the reaction conditions allowed us to obtain the new 2-(alkylamino)acetamides in good yields. These derivatives were characterized by spectroscopic methods and the structure of compound $\mathbf{3 b}$ was confirmed by X-ray analysis. The transformation of 2-(alkylamino)acetamides 3f, 3h and 3i into to the corresponding morpholine-2-ones was observed by ${ }^{1} \mathrm{H}$ NMR after 12 hours of reaction or upon standing in chloroform solution for one month. The transformation is thermodynamically favored through a preferred conformation, as determined by theoretical calculation of $\mathbf{3 h}$.

\section{Experimental Section}

General Procedures. NMR spectra were recorded on JEOL GXS-270, JEOL ECLIPSE-400 and Bruker Avance 300-DPX spectrometers in $\mathrm{CDCl}_{3}$ and DMSO- $\mathrm{d}_{6}$. Mass spectra were obtained with a Hewlett-Packard 5994-A instrument, and Infrared spectra were recorded as $\mathrm{KBr}$ pellets or in $\mathrm{CHCl}_{3}$ solution on a Perkin-Elmer 16F PC FT-IR spectrometer. Melting points were taken in open capillary tubes on a Gallemkamp MFB-595 apparatus and are uncorrected. The single-crystal X-ray study was performed on an ENRAF NONIUS CAD4 diffractometer. Reagents were purchased from Aldrich Co. Compound $3 \mathbf{b}, \mathrm{C}_{15} \mathrm{H}_{16} \mathrm{~N}_{2} \mathrm{O}$ (MW $=240.30$ ), crystallized in the space group $\mathrm{P} 2{ }_{1} / \mathrm{c}$, monoclinic, from chloroform/hexane as colorless rectangular prisms, size: $0.50 \times 0.44 \times 0.38 \mathrm{~mm}^{3}$ with $\mathrm{a}=6.225(10), \mathrm{b}=21.987(4), \mathrm{c}=9.552(2) \AA, \mathrm{V}=1307.3$ (4) $\AA^{3}$. Lattice constants were determined from least squares refinement on diffractometer angles for 24 automatically centered reflections; $\rho 1.221 \mathrm{Mg} / \mathrm{m}^{3}, \mathrm{Z}=4, \mu=0.078 \mathrm{~mm}^{-1}, \mathrm{~F}(000)=512$. Data collection: monitoring of check reflexion showed no signs of decay. A total of 2447 reflections were measured $\left(2>\theta>26^{\circ}\right)$, 
2304 were independent and of these 1737 were considered observed [Fo $>4.0 \sigma(\mathrm{Fo})]$. Absorption correction was not necessary. Solution and refinement: direct methods, all non-hydrogen atoms were refined anisotropically, all hydrogen were located by difference Fourier maps and refined with an overall isotropic thermal parameter, $\mathrm{R}=0.0365, \mathrm{Rw}=0.0954, \mathrm{w}=1 / \sigma^{2}, \mathrm{GOOF}=1.057$, parameter to data ratio 1:7.7, largest residual electron density peak/hole in the final difference map: $0.149 /-0.153 \mathrm{e} \AA^{-3}$. Atomic scattering factors were taken from the International Tables for X-ray Crystallography. ${ }^{14}$ Data reduction was performed by Jana $98 .{ }^{15}$ All calculations were carried out on a VAX 4000 computer using the SHELX 93 (sheldrick G. M.) program package. ${ }^{16}$

2-(3'-Hydroxymethylphenylamino)acetamide (3a). To a solution of $1.00 \mathrm{~g}(7.25 \mathrm{mmol})$ of 2 bromoacetamide in $60 \mathrm{~mL}$ of acetonitrile was added $0.89 \mathrm{~g}(7.25 \mathrm{mmol})$ of 3-aminobenzyl alcohol 2a and $1.09 \mathrm{~g}(10.88 \mathrm{mmol})$ of potassium bicarbonate at room temperature. The resulting suspension was refluxed and stirred during 6 hours. After being cooled to room temperature the suspension was filtered and the filtrate evaporated under vacuum to obtain a yellow solid, which was recrystallized from methanol/acetone to yield $0.95 \mathrm{~g} \mathrm{(73 \% )}$ of $3 \mathbf{a}$ as a white solid, mp 104$106^{\circ} \mathrm{C}$. IR: 3384, 3354, 3300, 3030, 2918, 2850, 1642, $1038 \mathrm{~cm}^{-1}(\mathrm{KBr}) . \mathrm{MS}: \mathrm{m} / \mathrm{z}(\%), 180\left(\mathrm{M}^{+}\right.$, 36), 136 (100), 44(21), 29 (8). Anal. Calcd. for $\mathrm{C}_{9} \mathrm{H}_{12} \mathrm{~N}_{2} \mathrm{O}_{2}$ (180.17): C, 59.99; H, 6.70; N, 15.54. Found: C, 59.70; H, 6.60; N, 15.57.

2-(Diphenylmethylamino)acetamide (3b). The reaction of $1.00 \mathrm{~g} \mathrm{(7.25} \mathrm{mmol)} \mathrm{of} \mathrm{2-bromoacetamide} \mathrm{in}$ $60 \mathrm{~mL}$ of acetonitrile, $1.37 \mathrm{~g}(7.25 \mathrm{mmol})$ of aminodiphenylmethane $2 \mathbf{b}$ and $1.09 \mathrm{~g}(10.88 \mathrm{mmol})$ of potassium bicarbonate gave a yellow solid, which was recrystallized from chloroform/hexane to yield $1.39 \mathrm{~g} \mathrm{(80 \% )}$ of $\mathbf{3 b}$ as a white solid, $\mathrm{mp} 102-104^{\circ} \mathrm{C}$. IR: 3432, 3340, 3178, 3024, 2930, 2856, 1672 $\mathrm{cm}^{-1}$ (KBr). MS: m/z (\%), 196 (2), 167 (100), 44 (15), 29 (34). Anal. Calcd. for $\mathrm{C}_{15} \mathrm{H}_{16} \mathrm{~N}_{2} \mathrm{O}$ (240.29): C, 74.97; H, 6.71; N, 11.65. Found: C, 74.66; H, 6.65; N, 11.54.

2-[Bis(diphenylmethy)amino]acetamide (3c). The reaction of $2.00 \mathrm{~g}(14.5 \mathrm{mmol})$ of 2 bromoacetamide in $120 \mathrm{~mL}$ of acetonitrile, $1.37 \mathrm{~g}(7.25 \mathrm{mmol})$ of aminodiphenylmethane $2 \mathbf{b}$ and $2.18 \mathrm{~g}(21.75 \mathrm{mmol})$ of potassium bicarbonate gave a white solid, which was recrystallized from chloroform to yield $1.83 \mathrm{~g}(85 \%)$ of $3 \mathrm{c}$ as a white solid, mp $172-174^{\circ} \mathrm{C}$. IR: $3310,3172,3024$, 2934, 2864, 1676, $1650 \mathrm{~cm}^{-1}$ (KBr). MS: m/z (\%), 253 (40), 167 (100), 44(58).

Anal. Calcd. for $\mathrm{C}_{17} \mathrm{H}_{19} \mathrm{~N}_{3} \mathrm{O}_{2}$ (297.35): C, 68.66; H, 6.44; N, 14.13. Found: C, 68.34; H, 6.57; N, 14.09.

(1'S,2'S)-2-[(2'-Phenyl-2'-hydroxy-1'-methylethyl)methylamino]acetamide (3d). The reaction of $1.00 \mathrm{~g}$ (7.25 mmol) of 2-bromoacetamide in $60 \mathrm{~mL}$ of acetonitrile, $1.20 \mathrm{~g}(7.25 \mathrm{mmol})$ of $(1 \mathrm{~S}, 2 \mathrm{~S})-(+)-$ pseudoephedrine $2 \mathbf{d}$ and $1.09 \mathrm{~g}(10.88 \mathrm{mmol})$ of potassium bicarbonate gave a yellow solid, which was washed with chloroform and precipitated from hexane to yield $1.43 \mathrm{~g} \mathrm{(89 \% )} \mathrm{of} \mathrm{3d} \mathrm{as} \mathrm{a} \mathrm{white}$ solid, mp 142-145 ${ }^{\circ} \mathrm{C}$. IR: 3414, 3304, 3084, 2932, 2858, 1638, $1028 \mathrm{~cm}^{-1}(\mathrm{KBr})$. MS: m/z (\%), 178 (2), 115 (100), 44 (90), 43 (21). Anal. Calcd. for $\mathrm{C}_{12} \mathrm{H}_{18} \mathrm{~N}_{2} \mathrm{O}_{2}$ (222.28): C, 64.84; H, 8.16; N, 12.60. Found: C, 64.52; H, 8.16; N, 12.24 .

(1'R,2'R)-2-[(2'-Phenyl-2'-hydroxy-1'-methylethyl)methylamino]acetamide (3e). The reaction of $1.00 \mathrm{~g}$ ( $7.25 \mathrm{mmol})$ of 2-bromoacetamide in $60 \mathrm{~mL}$ of acetonitrile, $1.20 \mathrm{~g}(7.25 \mathrm{mmol})$ of (1R,2R)-(-)pseudoephedrine $2 \mathbf{e}$ and $1.09 \mathrm{~g}(10.88 \mathrm{mmol})$ of potassium bicarbonate gave a yellow solid, which 
was washed with chloroform and precipitated from hexane to yield $1.35 \mathrm{~g}(84 \%)$ of $3 \mathbf{e}$ as a white solid, mp 142-145 ${ }^{\circ} \mathrm{C}$. IR: 3412, 3302, 3084, 2930, 2858, 1638, $1028 \mathrm{~cm}^{-1}(\mathrm{KBr}) . \mathrm{MS}: \mathrm{m} / \mathrm{z}(\%), 178$ (3), 115 (100), 44 (87), 43 (23). Anal. Calcd. for $\mathrm{C}_{12} \mathrm{H}_{18} \mathrm{~N}_{2} \mathrm{O}_{2}$ (222.28): C, 64.84; H, 8.16; N, 12.60. Found: C, 65.06; H, 8.36; N, 12.21 .

(1'R,2'S)-2-[(2'-Phenyl-2'-hydroxy-1'-methylethyl)methylamino]acetamide (3f). The reaction of $1.00 \mathrm{~g}$ ( $7.25 \mathrm{mmol})$ of 2-bromoacetamide in $60 \mathrm{~mL}$ of acetonitrile, $1.20 \mathrm{~g}(7.25 \mathrm{mmol})$ of (1R,2S)-(-)ephedrine $2 \mathrm{f}$ and $1.09 \mathrm{~g}(10.88 \mathrm{mmol})$ of potassium bicarbonate gave a yellow solid, which was washed with chloroform and precipitated from hexane to yield $1.33 \mathrm{~g}(83 \%)$ of $3 \mathbf{f}$ as a white solid, mp 88-91 ${ }^{\circ} \mathrm{C}$. IR: $3394,3316,3198,3032,2968,2924,2864,1678,1048 \mathrm{~cm}^{-1}(\mathrm{KBr})$. MS: m/z (\%), 178 (2), 115 (100), 44 (87), 43 (22). Anal. Calcd. for $\mathrm{C}_{12} \mathrm{H}_{18} \mathrm{~N}_{2} \mathrm{O}_{2}$ (222.28): C, 64.84; H, 8.16; N, 12.60. Found: $\mathrm{C}, 64.54 ; \mathrm{H}, 8.22 ; \mathrm{N}, 12.41 .{ }^{1} \mathrm{H}$ NMR data of (5S,6R)-4,5-dimethyl-6-phenyl-1,4oxazin-2-one $4 \mathbf{f}$ obtained from the spectrum of a mix with $3 \mathbf{f}, \delta_{\mathrm{H}}\left(\mathrm{CDCl}_{3}\right) 0.72\left(\mathrm{H}-8,{ }^{3} \mathrm{~J}=6.9 \mathrm{~Hz}\right)$, $2.33(\mathrm{H}-7), 3.04-3.15(\mathrm{H}-5), 3.43\left(\mathrm{H}-3_{\mathrm{A}},{ }^{2} J=18 \mathrm{~Hz}\right), 3.38\left(\mathrm{H}-3_{\mathrm{B}},{ }^{2} J=18 \mathrm{~Hz}\right), 5.59\left(\mathrm{H}-6,{ }^{3} J=3.29\right)$, 7.21-7.25 H-10,11,12).

(1'S,2'R)-2-[(2'-Phenyl-2'-hydroxy-1'-methylethyl)methylamino]acetamide (3g). The reaction of $1.00 \mathrm{~g}$ ( $7.25 \mathrm{mmol})$ of 2-bromoacetamide in $60 \mathrm{~mL}$ of acetonitrile, $1.46 \mathrm{~g}(7.25 \mathrm{mmol})$ of $(1 \mathrm{~S}, 2 R)-(+)$ ephedrine $2 \mathrm{~g}$ and $2.18 \mathrm{~g}(21.75 \mathrm{mmol})$ of potassium bicarbonate gave a yellow solid, which was washed with chloroform and precipitated from hexane to yield $1.28 \mathrm{~g} \mathrm{(79 \% )} \mathrm{of} 3 \mathrm{~g}$ as a white solid, mp 88-91 ${ }^{\circ} \mathrm{C}$. IR: 3394, 3316, 3198, 3032, 2968, 2924, 2864, 1678, $1048 \mathrm{~cm}^{-1}(\mathrm{KBr})$. MS: m/z (\%), 178 (2), 115 (100), 44 (95), 43 (19). Anal. Calcd. for $\mathrm{C}_{12} \mathrm{H}_{18} \mathrm{~N}_{2} \mathrm{O}_{2}$ (222.28): C, 64.84; H, 8.16; N, 12.60. Found: C, $64.54 ; \mathrm{H}, 8.22 ; \mathrm{N}, 12.42$.

Synthesis of 2-[(2'-Hydroxyethyl)methylamino]acetamide (3h). The reaction of $1.00 \mathrm{~g}$ (7.25 mmol) of 2-bromoacetamide in $60 \mathrm{~mL}$ of acetonitrile, $0.55 \mathrm{~g}(7.25 \mathrm{mmol})$ of 2(methylamino)ethanol $\mathbf{2 h}$ and $1.09 \mathrm{~g}(10.88 \mathrm{mmol})$ of potassium bicarbonate gave a viscous liquid, which was added chloroform and hexane to yield $0.93 \mathrm{~g} \mathrm{(97 \% )}$ of $3 \mathbf{h}$ as a yellow semi-solid. IR: 3388, 3328, 2948, 2846, 1670, 1588, $1078 \mathrm{~cm}^{-1}$. MS: m/z (\%), 88 (50), 44 (100), 43 (17). Anal. Calcd. for $\mathrm{C}_{5} \mathrm{H}_{12} \mathrm{~N}_{2} \mathrm{O}_{2}$ (132.16): C, 45.44; H, 9.15; N, 21.19. Found: C, 45.39; H, 9.44; N, 20.83. ${ }^{1} \mathrm{H}$ NMR data of 4-methyl-1,4-oxazin-2-one $4 \mathbf{h}$ obtained from the spectrum of a mix with $3 \mathbf{h}, \delta_{\mathrm{H}}$ $\left(\mathrm{CDCl}_{3}\right) 2.27(\mathrm{H}-7), 2.59\left(\mathrm{H}-5,{ }^{3} \mathrm{~J}=5.17 \mathrm{~Hz}\right), 3.19(\mathrm{H}-3), 4.36\left(\mathrm{H}-6,{ }^{3} \mathrm{~J}=5.19\right)$.

2-[Benzyl(2'-hydroxyethyl)amino]acetamide (3i). The reaction of $1.00 \mathrm{~g}(7.25 \mathrm{mmol})$ of 2 bromoacetamide in $60 \mathrm{~mL}$ of acetonitrile, $1.10 \mathrm{~g}(7.25 \mathrm{mmol})$ of 2-(benzylamino)ethanol $2 \mathbf{i}$ and $1.09 \mathrm{~g}(10.88 \mathrm{mmol})$ of potassium bicarbonate gave a yellow solid, which was recrystallized from chloroform/acetone to yield $1.33 \mathrm{~g}(88 \%)$ of $3 \mathbf{i}$ as white solid, mp $132-135^{\circ} \mathrm{C}$. IR: 3396,3300 , 3034 2934, 2862, 1638, 1082, cm ${ }^{-1}$ (KBr). MS: m/z (\%), 164 (22), 91 (100), 44 (6), 43 (11). Anal. Calcd. for $\mathrm{C}_{11} \mathrm{H}_{16} \mathrm{~N}_{2} \mathrm{O}_{2}$ (208.26): C, 63.44; H, 7.74; N, 13.45. Found: C, 63.52; H, 7.58; N, 13.15 . ${ }^{1} \mathrm{H}$ NMR data of 4-benzyl-1,4-oxazin-2-one $4 \mathbf{i}$ obtained from the spectrum of a mix with $3 \mathbf{i}, \delta_{\mathrm{H}}$ $\left(\mathrm{CDCl}_{3}\right) 2.64\left(\mathrm{H}-5,{ }^{3} J=5.19 \mathrm{~Hz}\right), 3.25(\mathrm{H}-3), 3.56(\mathrm{H}-7), 4.31\left(\mathrm{H}-6,{ }^{3} J=5.19\right), 7.1-7.6(\mathrm{H}-9,10,11)$. (2'S)-2[2'-Hydroxymethyl-1'-pyrrolidinyl]acetamide (3j). The reaction of $1.00 \mathrm{~g}(7.25 \mathrm{mmol})$ of 2bromoacetamide in $60 \mathrm{~mL}$ of acetonitrile, $0.73 \mathrm{~g}(7.25 \mathrm{mmol})$ of (S)-(+)-2-pyrrolidinemethanol $2 \mathbf{j}$ and $1.09 \mathrm{~g}(10.88 \mathrm{mmol})$ of potassium bicarbonate gave a yellow solid, which was washed with chloroform and precipitated from hexane to yield $1.03 \mathrm{~g}(90 \%)$ of compound $3 \mathbf{j}$ as white solid, $\mathrm{mp}$ 
63-66 ${ }^{\circ} \mathrm{C}$. IR: 3416, 3310, 2958, 2872, 1662, 1086, $\mathrm{cm}^{-1}$ (KBr). MS: m/z (\%), 114 (66), 127 (100), 44 (34), 43 (9). Anal. Calcd. for $\mathrm{C}_{7} \mathrm{H}_{14} \mathrm{~N}_{2} \mathrm{O}_{2}$ (158.20): C, 53.14; H, 8.91; N, 17.70. Found: C, 53.10; $\mathrm{H}, 8.55 ; \mathrm{N}, 17.29$.

Supplementary information. Crystallographic data for $\mathbf{3 b}$ has been deposited at the Cambridge Crystallographic Data Center, UK, CCDC as supplementary material No. 213603.

\section{Acknowledgments}

The authors thank the "Consejo Nacional de Ciencia y Tecnología (Conacyt-México)" for a scholarship to Luis S. Zamudio-Rivera and Hiram I. Beltrán and also for financial support, thanks to Dr. Rosa Luisa Santillan B. for reading the manuscript and for her helpful comments and Ing. Marco Antonio Leyva for his technical assistance in X-ray crystallography.

\section{References}

1. Basharov, M. A.; Vol'kenstein, M. V.; Golovanov I. B.; Grenader A. K.; Ermakov, G. L., Biofzikia 1986, 31, 741; Chem. Abstr. 1987, 106, 27367 u.

2. Napier, J. J.; Griffith, R. C. Eur. Pat. Appl. EP 356,035 (Cl.A61K31/135), 28 Feb. 1990, US Appl. 232,556, 12 Aug. 1988, 24pp; Chem. Abstr. 1990, 113, 190942f.

3. Baylina, E. G.; Llobet, P. P., Span. ES 497,077 (Cl. C07D279/02), 16 Jan 1982, Appl. 07 Nov 1980, 13 pp; Chem. Abstr. 1982, 97, 55826g.

4. Bondavalli, F.; Schenone, P.; Ranise A.; Filippelli, W.; Bile, G.; Filippelli, A.; Marmo, E. Farmaco Ed. Sci. 1983, 38, 57; Chem. Abstr. 1983, 99, 279s.

5. Dieter, R. K.; Deo, N.; Lagu, B.; Dieter, J. W. J. Org. Chem. 1992, 57, 1663.

6. Haiduc, I.; Silvestru, C. Organometallics in Cancer Chemotherapy, CRC Press, Boca Raton, Florida, 1989.

7. Lee, W. W. U. S. Pat. Appl. US 180,373, 09 Apr. 1982, Appl. 02 Aug. 1980, 13 pp Chem. Abstr. 1982, 97, 55811y.

8. Cantello, B. C. Eur. Pat. Appl. EP 99,707 (Cl. C07C93/04), 01 Feb. 1984, GB Appl. 82/20,645, 16 Jul. 1982, 87. Chem. Abstr. 1984, 101, 6799 t.

9. Levy, G. C.; Nelson, G. L. J. Am. Chem. Soc. 1972, 94, 4897.

10. Wasserman, H. J.; Ryan, R. R.; Layne, S. P. Acta Cryst. 1985, C41, 783.

11. Huheey, J. E.; Keiter, E. A.; Keiter R. L. Inorganic Chemistry, Principles of Structure and Reactivity; Harper Collins Colleges Publishers: New York. 1993; p 292.

12. Chassonnery, D.; Chastrette, F.; Chastrete M.; Blanc A.; Mattioda, G. Bull. Soc. Chim. Fr. 1994, $131,188$.

13. HyperChem. Molecular Modeling System, version 5.02, 1997. 
14. Cromer, D. T.; Waber, J. T. International Tables for X-Ray Crystallography, Kynoch Press: England, 1974, Vol. IV.

15. Pretricek, V. D. M. Jana 98 Program. Institute of Physics. Academy of Science of Czech Republic Praha, 1997.

16. Sheldrick, G. M. Shelx93 program for the refinement of crystal structures, 1993. 